\title{
Improving interchanges in China: the experiential phenomenon
}

\author{
Robin Hickman ${ }^{\mathrm{a}}$, Chia-Lin Chen ${ }^{\mathrm{a}}$, Andy Chow ${ }^{\mathrm{b}}$, Sharad Saxena ${ }^{\mathrm{c}}$ \\ ${ }^{a}$ Bartlett School of Planning, UCL, Central House, 14, Upper Woburn Place, London, WC1H 0NN, UK \\ ${ }^{\mathrm{b}}$ Centre for Transport Studies, UCL, Chadwick Building, Gower Street, London, WC1E 6BT, UK \\ ${ }^{c}$ Asian Development Bank, 6 ADB Avenue, Mandaluyong City 1550, Metro Manila, The Philippines
}

\begin{abstract}
This paper examines the development of multimodal passenger rail hubs as part of the highspeed rail (HSR) network in the People's Republic of China (PRC). The instrumental, attitudinal and affective experience of the journey through the interchange is assessed from the user perspective. Surveys are used from three HSR stations: Beijing South, Chengdu East and Suzhou North $(\mathrm{N}=150)$, representing three types of HSR stations, i.e. national capital, regional capital and sub-regional city. 'Expected' and 'realised' facilities are compared with the difference representing the 'disgruntlement' factor (after Stradling et al., 2007).

The unprecedented urbanisation process currently being witnessed in the PRC, together with the rapid development of the HSR network and associated multimodal interchanges, offers much opportunity to develop a leading-edge public transport system and urban development predicated on the use of public transport. Although the importance of intermodal interchange hubs is being increasingly recognised, the journey experience through the interchange often remains poor, with problems including Wi-Fi availability, waiting and seating, the availability of door-to-door ticketing, crowdedness, access to the hub, time of travel through and waiting in the hub. MANOVA analysis and factorial (three way) MANOVA analysis are used to explore the differences between intermodal hubs, with many instrumental and particularly attitudinal and affective factors being significantly influenced by location.
\end{abstract}

\section{Citation:}

Hickman, R., Chen, C.-L., Chow, A. \& Saxena, S. 2015. Improving interchanges in China: the experiential phenomenon Journal of Transport Geography, 42, 175-186.

https://doi.org/10.1016/j.jtrangeo.2014.12.004 


\section{Introduction}

Modern high speed rail (HSR) networks, developed since 1964 in Japan, and the 1970s in Europe (Hall, 2009), are now being considered, planned and built in many countries internationally. HSR connects major cities in France, Germany, Japan, Italy, the Netherlands, Taiwan, Turkey, South Korea, Spain, the United Kingdom - and, of course, in the People's Republic of China (PRC). If designed well, HSR can help to shape cities both in terms of travel behaviours and urban development - it can 'shrink spaces and shape places' (Banister et al., 2013). Investment in multimodal interchanges is a critical element of this wider enhancement of public transport infrastructure, and can contribute to achieving greater sustainability in travel at the city, metropolitan and regional scales.

Transport policy in Europe has sought, over many decades, to increase public transport mode share at the city and metropolitan scales and to reduce dependence on the private car for travel. There are extensive public transport networks often available at the city level, with continued investments to extend networks to new areas, within a context of relatively marginal urban population growth. Investment in public transport in some of the more progressive cities, such as in London, has been occurring for over 150 years, since the early days of the London Underground. For example, the Metropolitan Railway opened in 1863 and the development of the early railways in the UK occurred from the 1840s onwards. In comparison, the People's Republic of China (PRC) has a very different set of contextual issues, with rapid urbanisation and industrialisation processes, dramatic levels of in-migration to the cities from the surrounding rural areas, as well as large, and very recent, investments in public transport infrastructure and multi-modal interchanges. This includes the development of the largest HSR network in the world, a comprehensive expansion of urban metros, light rapid and bus rapid transit systems, highways and airports. The scale and speed of development in the PRC are both remarkable: the infrastructure plans and investment programmes, which took more than a century to develop in the European and other so-called 'developed' countries, are now being planned and implemented to very short timescales in the PRC - since 2007 in the case of HSR. The development of transport infrastructure and intermodal hubs is very closely associated with shaping space economies (Zhang et al., 2010) and assisting in the urbanisation process through new development and city expansion (Dai, 2011). Hence there is a strong element of using major transport infrastructure investment to help shape the growth of metropolitan areas.

The interchange is a critical part of HSR and the door-to-door journey, particularly where the journey has multiple links. It can help to develop the public transport journey as a valued activity, providing the means of linking public transport services together to form a network, and creating a better integration and transfer between modes. If transfers between services can be made easier, quicker, more convenient, more productive - and more enjoyable - then better, wider ranging and more frequent journeys are likely to be made by public transport (Chen et al., 2014). Time spent at the interchange and on the whole door-to-door public transport journey can be, in theory, designed as little different to being in the office or at home: the journey no longer perceived as 'wasted time', at least to an extent - as reading, working, listening to music, accessing entertainment, eating and drinking, daydreaming and people watching, become much easier to undertake, as valued activities. These activities can often be facilitated by the emerging information and communication technologies on offer (Lyons and Urry, 2005; Jain and Lyons, 2008).

The interchange hub can therefore perform two key functions: 
1. As an important element of the multiple link public transport journey (part of the internal interchange environment).

2. In providing the opportunity for hub area development. High density, mixed use development around the hub can help support the (re) development of city neighbourhoods, support patronage on public transport, and also improve vitality for the user experience in the hub (the external interchange environment).

The multimodal interchange in the PRC is often quite distinctive to the European model, with large, airport-style buildings, usually built on a multi-level basis. Ground level (first floor in the PRC) tends to be occupied by the rail lines and platform; the second floor provides space for the waiting hall and drive in and drop off; underground floor one is the departure and interchange level, with connections to the Metro if applicable, and also car parking and taxi pick up; underground floor one and two can provide space for the Metro lines. With such large spaces involved, the experiential nature of the interchange journey seems critical. We should remember that the experience of the public transport journey needs to be positive if to be repeated - in terms of the enjoyment of travel and also the potential for productivity. All of these issues are important if urban development in the PRC is to be predicated on the greater use of public transport. Alongside massive investment in public transport infrastructure, there has also been massive investment in highway infrastructure in cities in the PRC, and there is a great danger that cities and lifestyles are becoming very car dependent - in some, such as Beijing, this is already the case.

In the research literature (Table 1), the journey experience has been examined in terms of different attributes, including instrumental dimensions (relating to the practical aspects of travelling, such as journey time, cost, efficiency and flexibility), attitudinal dimensions (referring more to the perceived quality of facilities), and even affective dimensions (the feelings or emotions induced by travel, such as liking or disliking, pleasure or displeasure, boredom and stress). The utility of travel seems to be not only dependent on its instrumental value, but also on wider attitudinal and affective factors. The affective factors are particularly interesting, resulting from feelings or emotions, as a result of interaction with stimuli or a response to the 'situational cue' (Zajonc, 1980). The analysis within the transport field has moved from an understanding that travel may be more than a 'derived demand' (Mokhtarian and Salomon, 2001), to an examination of the motives for using the private car (such as Steg, 2005; Anable, 2005), with analysis by different public transport passenger segments and journey types (Anable and Gatersleben, 2005; Stradling et al., 2007; Price and Matthews, 2013; Carreira et al., 2013; Carreira et al., 2014). Useful approaches have been developed to measure the level of (dis)satisfaction of particular features across different modes (including Stradling et al., 2007).

Much of this work has been carried out from the European or 'developed' country perspective, and there is little research evident, to the knowledge of the authors, in the PRC or Asian context. In practice, the design of multimodal interchanges in the PRC, and elsewhere, has focused on planning for projected passenger volumes, in improving the instrumental features of travel, and there has been much less consideration of the attitudinal and affective experience of travel. Closely linked to this is the potential 'seamlessness' of travel (Hamiduddin et al., 2013). Seamlessness is defined as: "improving the overall door-todoor journey, not just the individual elements. Journeys need to be conceived and developed as coordinated, integrated, productive, enjoyable and easy to use, with points of 'friction' within and between different stages removed or reduced" (Hickman et al., 2013). The seamlessness of the journey can involve instrumental, attitudinal and affective factors - 
indeed all of these areas need to be improved to enhance the journey experience.

Table 1: Summary of Previous Literature on Understanding the Journey Experience

\begin{tabular}{|c|c|c|c|}
\hline \multicolumn{3}{|c|}{ Empirical Research on Journey Experience Factors } & \multirow{3}{*}{ 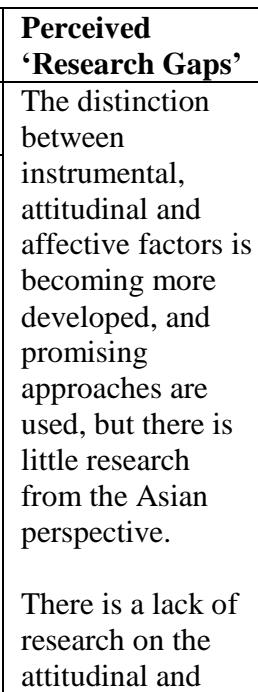 } \\
\hline $\begin{array}{l}\text { Transport } \\
\text { modes }\end{array}$ & Instrumental Factors & Attitudinal and Affective Factors & \\
\hline \multirow[t]{2}{*}{ Car } & $\begin{array}{l}\text { Research conventionally focuses on } \\
\text { instrumental motives for car usage: cost, } \\
\text { speed, flexibility and convenience (Steg, } \\
\text { 2005; Anable, 2005). }\end{array}$ & $\begin{array}{l}\text { Travel is much more than a derived } \\
\text { demand - it may also be desired for its } \\
\text { own sake (Mokhtarian and Salomon, } \\
\text { 2001). } \\
\text { Use of the car is popular for more than } \\
\text { instrumental reasons, including: } \\
\text { - Symbolic factors: the car (and its } \\
\text { brand) represents status and prestige } \\
\text { - Affective factors: fondness for } \\
\text { driving, car possession, freedom and } \\
\text { independence (Steg, 2005) } \\
\text { Most group differences are due to } \\
\text { symbolic and affective factors (Steg, } \\
\text { 2005). }\end{array}$ & \\
\hline & \multicolumn{2}{|c|}{$\begin{array}{l}\text { Different attitudinal segments are related to travel behaviour - policy responses can be } \\
\text { tailored to these different segments (Anable, 2005). }\end{array}$} & affective \\
\hline $\begin{array}{l}\text { Multiple } \\
\text { Modes }\end{array}$ & $\begin{array}{l}\text { For work journeys, more importance is given } \\
\text { to instrumental factors; there are also short } \\
\text { and long term effects (Anable and } \\
\text { Gatersleben, 2005) } \\
\text { - Convenience, predictability and } \\
\text { monetary costs (short) } \\
\text { - Health, fitness and the environment } \\
\text { (long) }\end{array}$ & $\begin{array}{l}\text { Affective factors - such as relaxation, no } \\
\text { stress, excitement, control, freedom - are } \\
\text { more important in leisure journeys (Anable } \\
\text { and Gatersleben, 2005). }\end{array}$ & $\begin{array}{l}\text { public transport } \\
\text { usage, particularly } \\
\text { for High Speed } \\
\text { Rail journeys, and } \\
\text { for important } \\
\text { parts of the } \\
\text { journey such as } \\
\text { the interchange. }\end{array}$ \\
\hline $\begin{array}{l}\text { Public } \\
\text { Transport } \\
\text { and } \\
\text { Interchanges }\end{array}$ & \multicolumn{2}{|c|}{$\begin{array}{l}\text { Public transport } \\
\text { - Customer experience and 'user disgruntlement' over a range of journey factors, such } \\
\text { as: reliability, frequency, weather protection (waiting and travelling), safety, fare } \\
\text { prices, cleanliness, wayfinding, convenience, comfort, cost, ticketing (Stradling et } \\
\text { al., 2007) } \\
\text { Bus services } \\
\text { - Subjective and objective measures of transit performance are developed using } \\
\text { performance measures and passenger perceptions, hence measured and perceived } \\
\text { service quality can be compared (Eboli and Mazzulla, 2011). } \\
\text { Desired quality of bus service provision - with waiting time, cleanliness and comfort } \\
\text { most valued (dell'Olio et al., 2011). } \\
\text { Experience factors and experience components are examined within tourist and } \\
\text { intercity mid-distance bus trips (Carreira et al., 2013). } \\
\text { Seven dimensions of experience factors, including individual space and information } \\
\text { Accessibility to rail services } \\
\text { Mode of access to the interchange is not affected by car availability; but the quality } \\
\text { of the station and the perception of the access and egress journey, including } \\
\text { connections to public transport, capacity of car parks, and quality of cycle parking, } \\
\text { affects overall satisfaction with the journey (Givoni and Rietveld, 2007). } \\
\text { Door-to-door rail journey } \\
\text { There are 'hard' dimensions (travel time, reliability, service schedule, price) and } \\
\text { 'soft' dimensions (personal safety, comfort, information services) associated with the } \\
\text { customer experience (Brons and Rietveld, 2009). } \\
\text { Interchange } \\
\text { Metro/rail interchanges include dimensions of efficiency, usability, understanding } \\
\text { and quality, and best practice guidelines are developed (TfL, 2009; Taylor, 2012). } \\
\text { The interchange includes elements of the waiting environment, information } \\
\text { provision, services (interval, frequency, reliability and efficiency), queuing, ticketing } \\
\text { and customer care. Many aspects of the interchange are perceived negatively by } \\
\text { users (Hine and Scott, 2000). }\end{array}$} & $\begin{array}{l}\text { There is little } \\
\text { understanding of } \\
\text { the differential } \\
\text { experience across } \\
\text { interchanges, or } \\
\text { the importance of } \\
\text { particular } \\
\text { instrumental and } \\
\text { attitudinal or } \\
\text { affective factors. }\end{array}$ \\
\hline
\end{tabular}


This paper seeks to address the perceived research gaps ${ }^{1}$, examining the experience of travel through interchanges in the PRC, the differential experience across interchanges, and the relative importance of instrumental, attitudinal and affective factors. The analysis is structured in two main parts: firstly, the development of HSR and multimodal hubs in the PRC are considered; and, second, through a survey of three recently completed multimodal interchanges on new HSR lines, the instrumental, attitudinal and affective nature of the journey experience through the interchange is explored. It is hoped that the paper will contribute to the current debate on the design of HSR hubs in the PRC, in particular concerning the role of the interchange in enhancing the door-to-door public transport journey experience and in wider urban development at the city level.

\section{The Development of HSR Hubs in the PRC}

Since economic reform in the late 1970s, rapid industrialisation has dramatically changed urban China, resulting in unprecedented spatial-economic growth. The demographic transition from rural to urban areas is associated with a move from an agriculture-based economy to manufacturing, technology and service industries. In just 30 years, the urbanisation rate in the PRC has more than doubled, from 19 per cent in 1980 to 52 per cent in 2012 (World Bank, 2013). 11 cities currently have populations at over 5 million (at the urban area level) and three of these are over 10 million - Chongqing, Shanghai and Beijing. The wider metropolitan populations are even larger. In 2007, the National Development and Reform Commission (NDRC) announced 10 designated mega-city regions (MCRs), including three around the major coastal economic zones and seven in inland China. These MCRs amount to around 10 per cent of the national land area, but their productivity accounts for more than half of the national total output in terms of GDP (Xiao and Yuan, 2007). An additional 300 million Chinese rural dwellers are likely to move to cities over the next 20 years, meaning that up to 75 per cent of the population are likely to live in urban areas (Chen et al., 2014).

The comparison of the PRC to Europe is instructive (Table 2). The urbanisation rate is much lower in the PRC (52\%) relative to Europe (74\%), Gross Domestic Product (GDP) is nearly at $50 \%$ and Gross National Income (GNI) per capita at nearly $20 \%$ of European levels. GDP growth is much higher in the PRC, CO2 emissions a little lower, and vehicle ownership much lower.

Table 2: PRC and Europe Comparison - World Development Indicators

\begin{tabular}{|l|c|c|}
\hline Indicator (2012 data unless stated) & PRC & European Union \\
\hline Population (persons) & 1.35 billion & 509 million \\
Urban population $(\%)$ & $52 \%$ & $74 \%$ \\
GDP (US\$) & $\$ 8.23$ trillion & $\$ 16.69$ trillion \\
GNI per capita, Atlas method (US\$) & $\$ 5,720$ & $\$ 33,641$ \\
GDP growth (\%) & $7.8 \%$ & $-0.4 \%$ \\
CO2 emissions (metric tons per capita, 2010) & 6.2 & 7.4 \\
Motor vehicles/1000 people (2010) & 58 & 593 \\
\hline
\end{tabular}

(World Bank, 2013)

Rapid urbanisation in the PRC has led to unprecedented mobility growth - in the use of the motor car and also in public transport, but with a decline in the use of cycling and walking in most cities, which were at very high levels just 20 years ago. Cycling accounted for over 50\%

\footnotetext{
${ }^{1}$ Much of the research reported on in this paper was carried out as part of a project on 'Improving Interchanges' for the Asian Development Bank: Chen, C.-L., Hickman, R. \& Saxena, S. 2014. Improving Interchanges. Towards Better Multimodal Hubs in the PRC. Manila: Asian Development Bank.
} 
of trips in most cities just two decades ago. The growth in modern HSR networks in the second half of the 20th century has contributed to the renaissance in the use of public transport. In the last 10 years, the PRC has overshadowed the rest of the world in building its HSR network, developing at an unprecedented scale and speed (Figure 1). Since 2007, nearly $10,000 \mathrm{~km}$ of HSR lines have been built in the PRC. The number of rail passengers has increased from below 1,200 million in 2005 to 1,800 million in 2011, an increase of nearly $9 \%$ per annum. By 2020, the network is expected to connect all of the provincial cities and other cities with a population of over half a million (Zhang et al. 2010). The network will extend to approximately $18,000 \mathrm{~km}$, amounting to more than half of the overall length of HSR network in the world (Chen, 2012; Chen et al., 2014).

\section{Figure 1: The Current HSR Network Development Plan in the PRC}

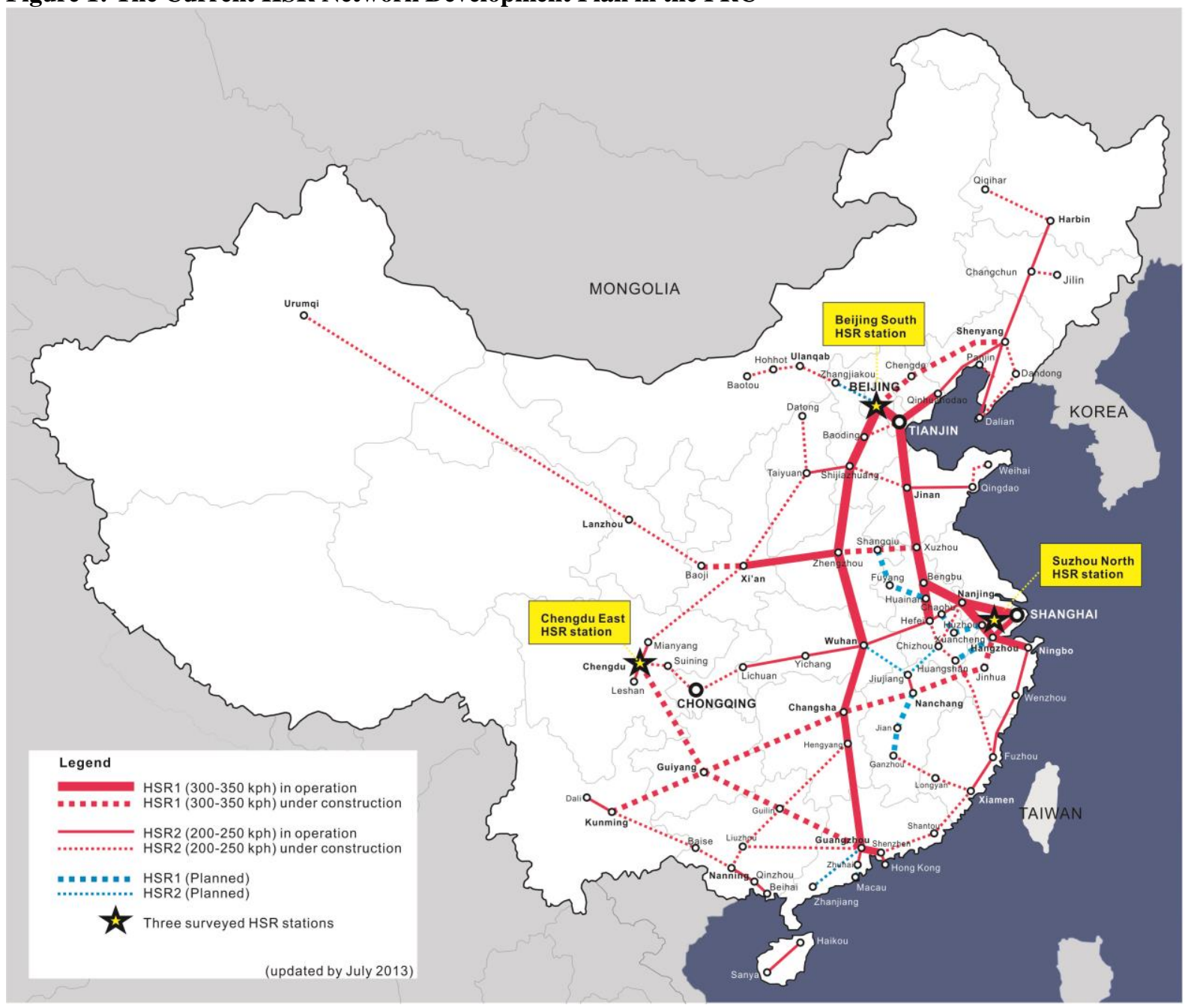

Key: HSR hubs and lines constructed and planned in the PRC for 2011-2015, Twelfth Five-Year Plan, 2011-2015 (National People’s Congress, 2011) (Chen et al., 2014).

Multimodal interchange hubs are very different in scale in the PRC, ranging from the 'super large', to 'large', 'medium', 'small' and 'basic' hubs. The specification of facilities differs according to the nature and scale of the hub (Figure 2). The position of a station in the hierarchy is determined by the operational volume of passengers, luggage, freight, and marshalling vehicles. The volume of goods and passengers transported in each station varies with time, so the ranking of stations may change accordingly. In 2013, the available data showed that approximately 50 stations are viewed as 'super large', 190 stations as 'large', and a large number below - there are over 5,500 stations classified in the PRC. 
Figure 2: A Hierarchy of Rail Hubs in the PRC

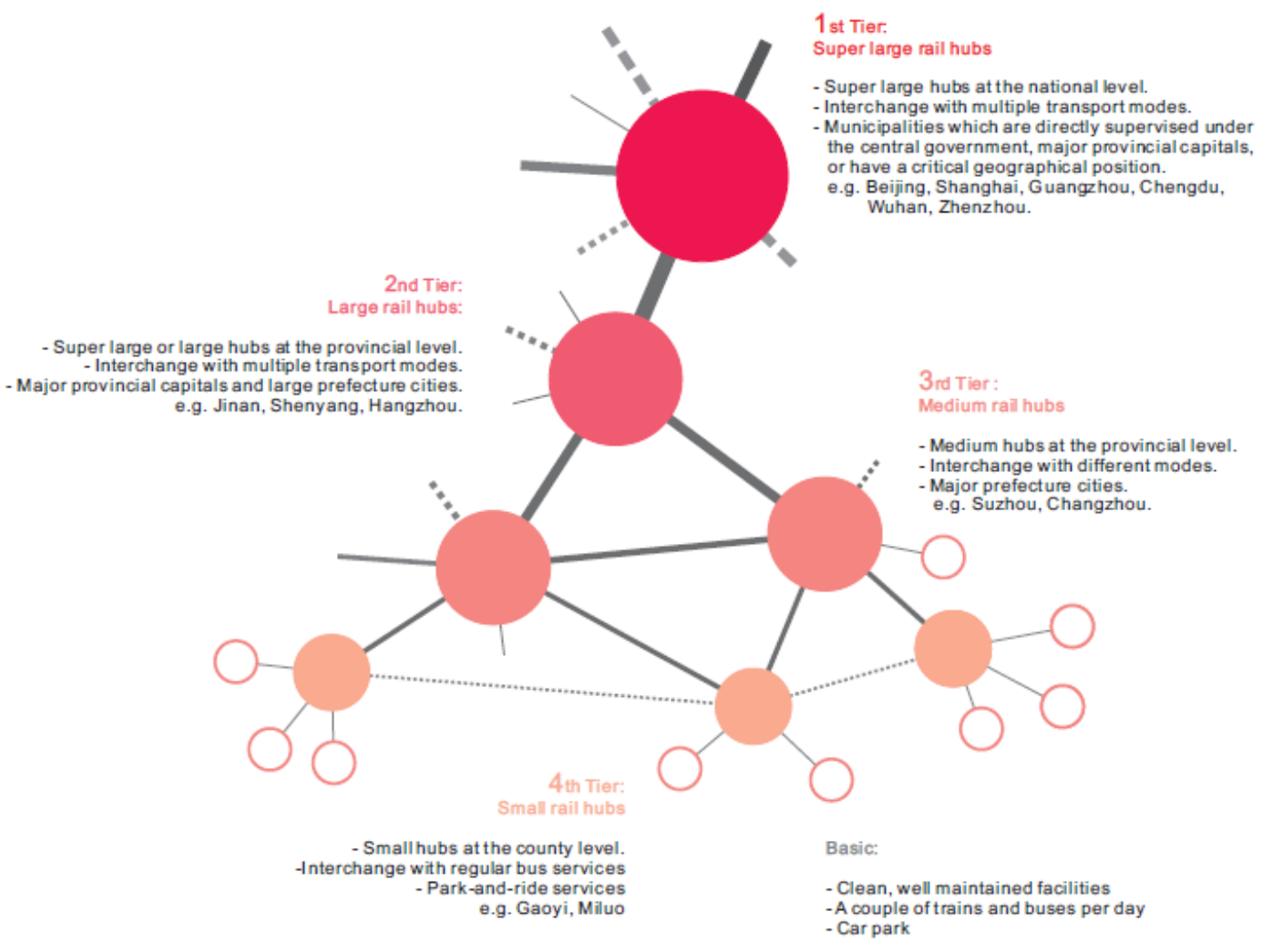

(Chen et al., 2014)

For each type of station, there are various expected facilities, summarised in Table 3, as derived from the Ministry of Railways (2007) and the Third Railway Survey and Design Institute (2005). There are requirements for the station plaza, such as plaza size and green space; and also the station building, such as concourse size, escalator provision, waiting rooms, provision for selling tickets; and passenger services, such as luggage store, toilets and signage.

Table 3: Station Hierarchy and Expected Facilities

\begin{tabular}{|c|c|c|c|c|c|c|}
\hline \multirow{2}{*}{$\begin{array}{l}\text { Facilities } \\
\text { Station Plaza } \\
\end{array}$} & \multicolumn{2}{|l|}{ Details } & \multirow{2}{*}{$\begin{array}{l}\text { Super } \\
\text { Large }\end{array}$} & \multirow[t]{2}{*}{ Large } & \multirow[t]{2}{*}{ Medium } & \multirow[t]{2}{*}{ Small } \\
\hline & Size & $>=4.8 \mathrm{~m}^{2}$ per head & & & & \\
\hline & Vertical plaza & & $\nabla$ & $\nabla$ & & \\
\hline & Green space & $>=10 \%$ & & & & \\
\hline \multirow{8}{*}{$\begin{array}{l}\text { Station } \\
\text { Building }\end{array}$} & Concourse & & $\nabla$ & $\nabla$ & $\nabla$ & \\
\hline & Concourse size & $>=0.2 \mathrm{~m}^{2}$ per head & & & & \\
\hline & Escalator and lift & & $\nabla \nabla$ & $\nabla \nabla$ & $\nabla$ & \\
\hline & Entry concourse & $\begin{array}{l}\text { Services for enquiry, post and } \\
\text { telecom }\end{array}$ & च曰 & ஏ■ & & \\
\hline & Leaving concourse & Services for telecom and toilets & $\nabla \square$ & 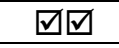 & & \\
\hline & Waiting rooms & Size $>=1.2 \mathrm{~m}^{2}$ per head & & & & \\
\hline & Waiting rooms & Normal & $87.5 \%$ & $88.0 \%$ & $92.5 \%$ & $100 \%$ \\
\hline & & Soft seats & $2.5 \%$ & $2.5 \%$ & $2.5 \%$ & $x$ \\
\hline
\end{tabular}




\begin{tabular}{|c|c|c|c|c|c|}
\hline & VIP space & $2.5 \%$ & $2.0 \%$ & $2.0 \%$ & $x$ \\
\hline & Solders (groups) & $3.5 \%$ & $3.5 \%$ & $x$ & $x$ \\
\hline & Persons with disabilities & $4.0 \%$ & $4.0 \%$ & $3.0 \%$ & $x$ \\
\hline $\begin{array}{l}\text { Space for selling } \\
\text { tickets }\end{array}$ & Ticket hall & 口曰 & 口曰 & च曰 & $x$ \\
\hline & $\begin{array}{l}\text { Ticket selling window (total } \\
\text { number) DP }\end{array}$ & $>=100$ & $50-100$ & $15-50$ & $2-4$ \\
\hline & $\begin{array}{l}\text { Ticket selling window (total } \\
\text { number) MP }\end{array}$ & $>=55$ & $25-50$ & $5-20$ & $2-4$ \\
\hline & $\begin{array}{l}\text { Size for each ticket selling } \\
\text { window }\end{array}$ & $>=24 \mathrm{~m}^{2}$ & $>=20 \mathrm{~m}^{2}$ & $>=16 \mathrm{~m}^{2}$ & $>=16 \mathrm{~m}^{2}$ \\
\hline & Ticket selling room (with staff) & च口 & पవ & 可 & चవ \\
\hline Passenger services & Enquiry services & 啫 & 啫 & 啫 & \\
\hline & Small luggage storage & 哂 & 吅 & 哽 & \\
\hline & Smoking zone & 呵 & 啫 & & \\
\hline & Infirmary & पవ & पవ & प्र & \\
\hline & Toilet & पच口 & च口 & 可 & चV \\
\hline & Small commercial facilities & 四 & $\square$ & V & 四 \\
\hline & Signage for directions & 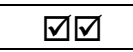 & पవ & 可 & पच口 \\
\hline & Water services & च口 & पవ & 可 & चవ \\
\hline
\end{tabular}

$\mathrm{DP}=$ dedicated passenger rail stations; $\mathrm{MP}=$ mixed freight and passenger rail stations; $\mathrm{m}^{2}=$ metre squared; $\square \square$

= "must have" facility; $\square=$ recommendation; $X=$ not necessary.

(Chen et al., 2014)

\section{The Journey Experience in Selected Interchanges in the PRC}

\subsection{The Instrumental, Attitudinal and Affective Experience}

A standards-based approach can perhaps only take the design of intermodal hubs so far. Intermodal hubs are often designed primarily in terms of operational efficiency, with little consideration for the quality of the journey experience. Developing an attractive journey experience is more difficult, but remains central to the success (or otherwise) of the interchange. Important here are instrumental, attitudinal and affective issues, for example, the journey needs to be quick and convenient, but also there should be an appropriate level of attention given to the quality of facilities throughout the journey. In some of the leading PRC stations, and wider international stations, there is a growing understanding of the importance of travel journey satisfaction - but the good practice is fairly limited in application.

In the UK context, Stradling et al. (2007) develop a 'user disgruntlement' index, considering how well an aspect of a transport service is being delivered relative to the perceived user importance that this is delivered well. This approach draws on research concerning customer service provision, which suggests that customer satisfaction is related to the perceived discrepancy between actual and ideal levels of service delivery. There are difficulties measuring expected and perceived satisfaction, however calculating the gaps between these levels, and weighting these by perceived importance can help to reveal which areas of improvement are most required in the design of transport services. Considering instrumental, attitudinal and affective issues within this disgruntlement framework can help examine the range of factors that are likely to be deemed as important to the user and that can be improved in the design of interchanges.

\subsection{Interchange Survey Approach}

Drawing on the above approach, passenger surveys were carried out at rail hubs in Beijing South (BS), Chengdu East (CE), and Suzhou North (SN), representing super large, large and 
medium rail hubs. 150 surveys were used ${ }^{2}, 50$ at each hub, comparing the expected and actual facilities found. The survey was designed to investigate 8 instrumental and 22 attitudinal/affective factors regarding the interviewees' interchange experiences (see Figure 3). To survey each of these 30 experiences, the interviewees were asked the following type of questions:

Question A. "When you make this type of interchange it is important that ..." Question B. "What was your experience of the interchange ..."

Survey participants were chosen randomly. However, given the massive scale of the highspeed rail stations and the large number of passengers, choosing people for survey was a challenge. A questionnaire of 30 questions needed at least 10 minutes to complete; in most cases, explanations and communications were required for clarification. Thus, people who were sitting and waiting for their trains were more willing to accept the survey than those who had just arrived by HSR or were about to leave. In all three surveyed HSR stations, more than $60 \%$ of questionnaires were conducted while participants were waiting for trains (in Chengdu East HSR station, the percentage was 80\%).

Tables 4-6 show the descriptive statistics for survey respondents, relative to the average for the PRC. Male and female participants are at $56 \%$ and $44 \%$ for all three stations, close to the national figures of $51 \%$ and $49 \%$ in 2010 . Beijing South has a higher percentage of male respondents and Chengdu East a marginally lower percentage of male respondents. The survey respondents are unrepresentative of the national level in age terms, with a large proportion of 20-40 year olds, and few in the over 60 or under 20 year old categories. The purposes of trips are mainly for business, tourism and visiting families. These three purposes account for more than $70 \%$ of all trips made. In Suzhou North HSR station, the figure was at $90 \%$. Transport modes to and from the hubs varies quite markedly; for the HSR station interchanging with Metro (Beijing South and Chendu East), then Metro is the preferred access and egress mode. In contrast, Suzhou North has no Metro services and showed a mixture of three modes: bus (29\%), taxi (29\%), and car (21\%) in terms of arrivals. Travel mode from the hub is predominantly rail, showing that most survey respondents were just about to board the rail services. The data illustrates that the stations surveyed are quite different in character.

Table 4: Survey Respondents' Gender and Age Range

\begin{tabular}{|l|c|c|c|c|c|c|}
\hline \multirow{2}{*}{ Location } & \multicolumn{2}{|c|}{ Gender } & \multicolumn{4}{c|}{ Age Range } \\
\cline { 2 - 7 } & Male & Female & $<20$ & $\mathbf{2 0 - 4 0}$ & $\mathbf{4 0 - 6 0}$ & $\mathbf{6 0 - 8 0}$ \\
\hline Beijing South & $64 \%$ & $36 \%$ & $10 \%$ & $76 \%$ & $12 \%$ & $2 \%$ \\
\hline Chengdu East & $48 \%$ & $52 \%$ & $2 \%$ & $72 \%$ & $26 \%$ & $0 \%$ \\
\hline Suzhou North & $56 \%$ & $44 \%$ & $4 \%$ & $77 \%$ & $17 \%$ & $2 \%$ \\
\hline Average (3 stations) & $56 \%$ & $44 \%$ & $5 \%$ & $75 \%$ & $18 \%$ & $1 \%$ \\
\hline $\begin{array}{l}\text { Average (PRC) in 2010* (The } \\
\text { Sixth National Census, 2010) }\end{array}$ & $51 \%$ & $49 \%$ & $24 \%$ & $33 \%$ & $29 \%$ & $12 \%$ \\
\hline
\end{tabular}

*Note the national median average age is 36.3 (in 2012). The census in China is conducted every 10 years. The Sixth National Census was carried out in 2010 and is the latest one.

Source: National Bureau of Statistics of China (2012) China Population and Employment Statistics Yearbook, 2011, Beijing: China Statistics Press.

\footnotetext{
${ }^{2}$ The surveys were carried out by three local survey groups, led by Liang Zhao of Tsinghua University (for Beijing South), Yi-Wen Wang of Xi'an Jiatong-Liverpool University (Suzhou North) and Xianmin Mai of Southwest University for Nationalities (Chengdu East), as part of the Improving Interchanges project for the ADB (Chen et al., 2014).
} 
Table 5: Survey Respondents' Journey Purpose and Mode

\begin{tabular}{|c|c|c|c|c|c|c|}
\hline \multirow[b]{2}{*}{ Location } & \multicolumn{6}{|c|}{ Journey Purpose } \\
\hline & Commuting & Business & Tourism & Visiting & Migration & Other \\
\hline Beijing South & $8 \%$ & $34 \%$ & $14 \%$ & $22 \%$ & $6 \%$ & $16 \%$ \\
\hline Chengdu East & $0 \%$ & $26 \%$ & $28 \%$ & $20 \%$ & $6 \%$ & $2 \%$ \\
\hline Suzhou North & $4 \%$ & $35 \%$ & $24 \%$ & $31 \%$ & $0 \%$ & $6 \%$ \\
\hline
\end{tabular}

Table 6: Travel Modes to and from Hubs

\begin{tabular}{|c|c|c|c|c|c|c|c|c|c|}
\hline \multirow[b]{2}{*}{ Location } & \multicolumn{9}{|c|}{ Travel Mode to Hub } \\
\hline & Bus & Express & Metro & Taxi & Car & Railway & Cycle & Walk & Other \\
\hline Beijing South & $16 \%$ & $0 \%$ & $58 \%$ & $8 \%$ & $0 \%$ & $12 \%$ & $0 \%$ & $2 \%$ & $4 \%$ \\
\hline Chengdu East & $4 \%$ & $0 \%$ & $46 \%$ & $10 \%$ & $22 \%$ & $18 \%$ & $0 \%$ & $0 \%$ & $0 \%$ \\
\hline Suzhou North & $29 \%$ & $10 \%$ & $2 \%$ & $29 \%$ & $21 \%$ & $8 \%$ & $0 \%$ & $0 \%$ & $0 \%$ \\
\hline
\end{tabular}

\begin{tabular}{|c|c|c|c|c|c|c|c|c|c|}
\hline \multirow[b]{2}{*}{ Location } & \multicolumn{9}{|c|}{ Travel Mode from Hub } \\
\hline & Bus & Express & Metro & Taxi & Car & Railway & Cycle & Walk & Other \\
\hline Beijing South & $2 \%$ & $2 \%$ & $20 \%$ & $2 \%$ & $2 \%$ & $70 \%$ & $0 \%$ & $2 \%$ & $0 \%$ \\
\hline Chengdu East & $6 \%$ & $4 \%$ & $6 \%$ & $2 \%$ & $0 \%$ & $80 \%$ & $0 \%$ & $0 \%$ & $2 \%$ \\
\hline Suzhou North & $13 \%$ & $0 \%$ & $0 \%$ & $0 \%$ & $26 \%$ & $61 \%$ & $0 \%$ & $0 \%$ & $0 \%$ \\
\hline
\end{tabular}

\subsection{Interchange Survey Analysis}

As the first part of the survey method, elements of potential interchange hub facilities were identified from the literature (from Hine and Scott, 2000; Stradling et al., 2007; Givoni and Rietveld, 2007; Green and Hall, 2009; Brons and Rietveld, 2009; Transport for London, 2009; Metrolinx, 2011; UIC International Union of Railways, 2011; Taylor, 2012) and also in discussion with the Asian Development Bank and local interchange architects in the PRC. Survey respondents were asked to give scores on a Likert scale ranging from strongly disagree (score 1) to strongly agree (score 5). The instrumental, attitudinal and affective experiences of the respondents were analysed, for the most part, in terms of their score differences between Questions A and B, hence the focus is on the level of perceived disgruntlement (after Stradling et al., 2007). For example, if a respondent gave a score ' 5 ' on a particular factor for Question A (i.e. the expectation before using the hub), while gave a score '2' on the same factor for Question B (i.e. the actual experience after using the hub), the disgruntlement score on that particular factor will be considered to be $5-2=$ ' 3 '.

In terms of expected facilities, the aggregate scores for all three stations gave the following highest scores. There are perhaps some surprises in terms of priority, but include a mix of instrumental (I) and attitudinal/affective (A) factors (Figure 3):

- (A) I can use one ticket for the door-to-door journey (3.93)

- (I) Access to the interchange is easy (3.61)

- (I) It is quick to buy a ticket (3.57)

- (I) Signing is clear and easy to understand where to go (3.57)

- (A) I feel safe and secure in the hub (3.53)

- (I) I can easily find electronic timetable information (3.50)

- (A) There are facilities for people with disabilities and luggage (3.47)

- (I) Walking distance is short (3.40)

The largest disgruntlement levels relative to expected provision, again using the aggregate scores for all three stations, are given below, with a greater predominance on attitudinal/affective (A) issues (Figure 3):

- (A) Wi-Fi is available and free (1.09) 
- (A) There are places to sit and wait (0.97)

- (A) I can use one ticket for the door-to-door journey (0.96)

- (A) The hub is not too busy with other people (0.90)

- (I) Access to the interchange is easy (0.86)

- (A) There are facilities for people with disabilities and luggage (0.84)

- (I) There is little time to wait (0.81)

- (A) The staff at the interchange are pleasant and helpful $(0.71)$

The average disgruntlement factor is quite high ( 0.58 out of a possible score of 5 , which can be viewed as a service dissatisfaction level of 12\%) and for almost all service features there is a level of dissatisfaction. Also, relative to similar analysis in Europe (Hickman et al., 2012), it seems that Chinese travellers expect 'less' of their interchanges and score realised facilities 'better'. There is perhaps a cultural dimension here, with many users of interchanges in the PRC using only their local or neighbouring stations, hence the comparison to the interchange 'potential' (the national and international benchmarks) is often not made. The contextual specificity of the results is an area that could be examined further in additional research.

Figure 3: The User Experience in Interchanges in the PRC - Three Stations (Aggregate)

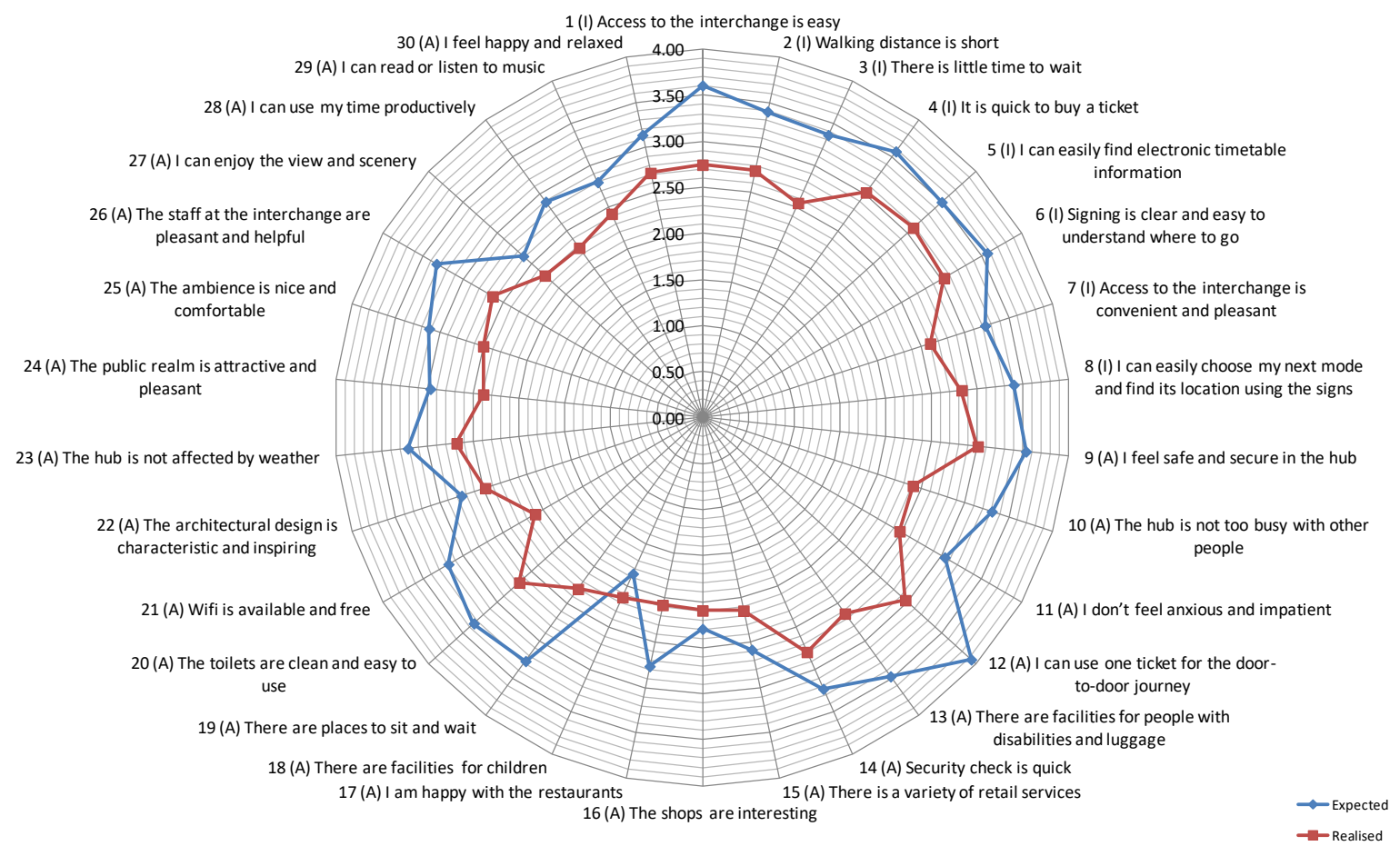

The 'disgruntlement level' - the difference between expected and realised criteria (scores out of 5) can be seen in the gap between the blue and red lines.

(I) Instrumental factor

(A) Attitudinal/affective factor

Many of the areas with high disgruntlement scores are attitudinal/affective issues and very important to the journey experience. These types of issues can be much improved in interchange design in the PRC (Chen et al., 2014) - there is often poor provision for waiting, 
for seating, for accessing Wi-Fi, for being 'productive' during the waiting time (in working, reading or accessing information), and for the browsing of retail or other commercial outlets.

Similar analysis was developed for the individual interchanges (Figure 4), and there are some differences in the user experience between the different stations. Beijing South has the highest disgruntlement scores, with dissatisfaction over places to sit and wait (1.35), the hub is not too busy (1.28), Wi-Fi availability (1.20), the ambience and comfort (1.04); Chengdu East has dissatisfaction over the availability of door-to-door ticketing (1.24), Wi-Fi availability (1.02), restaurants (0.88), and the speed of the security check (0.72); whilst Suzhou North has dissatisfaction in the restaurants (1.27), facilities for people with disabilities and luggage (1.25), places to sit and wait (1.23) and access to the interchange (1.12). There are no facilities for children at Suzhou North, and this was scored as zero for an expected and realized factor. Suzhou North has the highest average disgruntlement factor of all the three stations surveyed at 0.62 . 
Figure 4: The User Experience in Interchanges in the PRC - Three Stations (Disaggregate)

\section{SUZHOU NORTH}

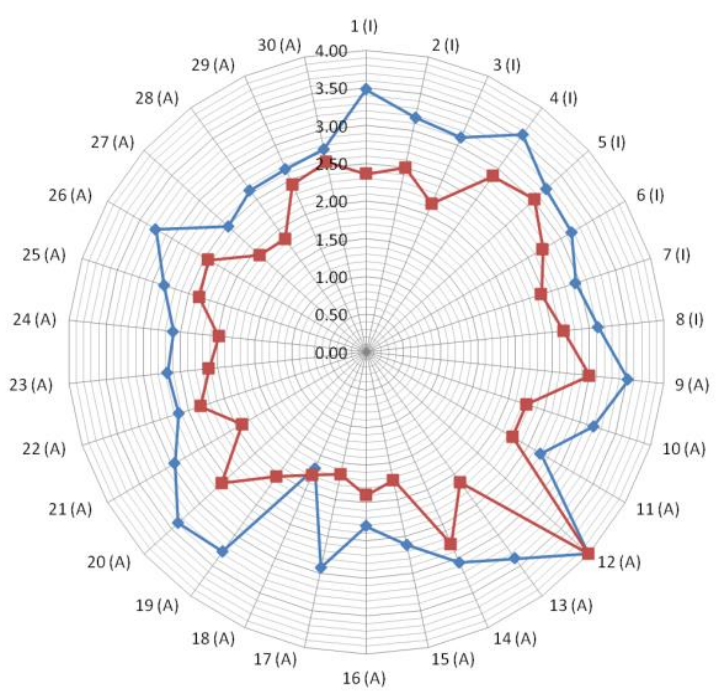

KEY

1 (I) Access to the interchange is easy

2 (I) Walking distance is short

3 (I) There is little time to wait

4 (I) It is quick to buy a ticket

5 (I) I can easily find electronic timetable information

6 (I) Signing is clear and easy to understand where to go

7 (I) Access to the interchange is convenient and pleasant

8 (I) I can easily choose my next mode and find its location using the signs

9 (A) I feel safe and secure in the hub

10 (A) The hub is not too busy with other people

11 (A) I don't feel anxious and impatient

12 (A) I can use one ticket for the door-to-door journey

13 (A) There are facilities for people with disabilities and luggage

14 (A) Security check is quick

15 (A) There is a variety of retail services

16 (A) The shops are interesting

17 (A) I am happy with the restaurants

18 (A) There are facilities for children

19 (A) There are places to sit and wait

20 (A) The toilets are clean and easy to use

21 (A) Wi-Fi is available and free

22 (A) The architectural design is characteristic and inspiring

23 (A) The hub is not affected by weather

24 (A) The public realm is attractive and pleasant

25 (A) The ambience is nice and comfortable

26 (A) The staff at the interchange are pleasant and helpful

27 (A) I can enjoy the view and scenery

28 (A) I can use my time productively

29 (A) I can read or listen to music

30 (A) I feel happy and relaxed

\section{BEIJING SOUTH}

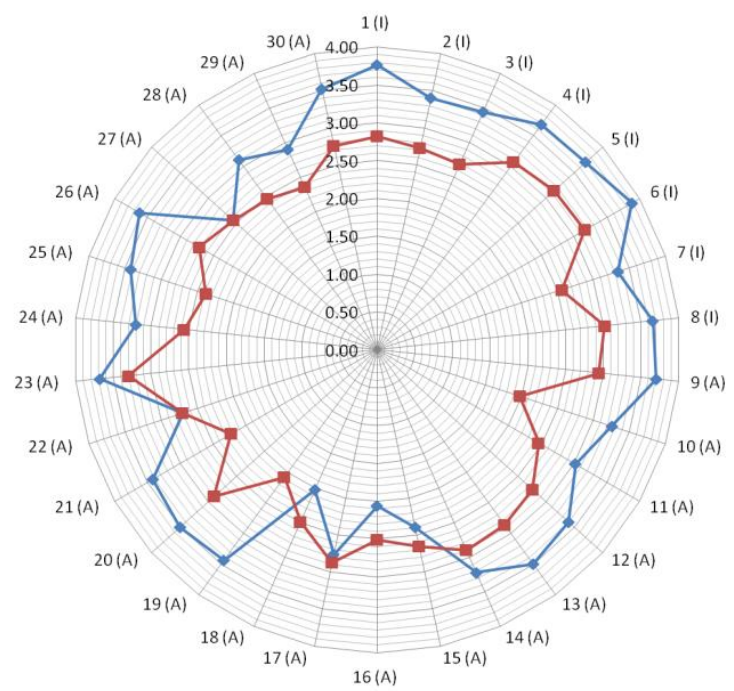

CHENGDU EAST

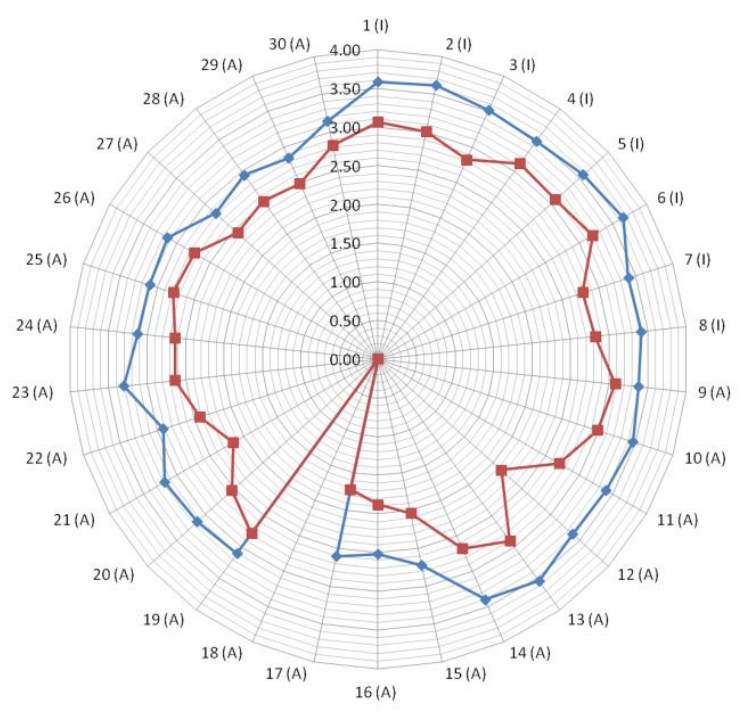

A MANOVA analysis (multivariate analysis of variance) is conducted to determine whether different interchange hubs will have an influence on the interchange experience. The results are summarised in Table 7. Each factor in the first column refers to the 8 instrumental and 22 attitudinal questions. The second, third and fourth columns list the average scores at each hub, where the ' $N$ ' in the first row states the sample sizes at the associated hub. The fifth and sixth columns show the F-statistics and the corresponding $p$-values regarding the hypothesis of whether different hubs will influence the interchange experiences. A smaller $p$-value will suggest a different hub will have a significant influence on the associated experience. The 
analysis reveals that only a few of the interviewees' instrumental experiences, but most of their attitudinal/affective experiences, are influenced by the particular interchange hub. For example, the instrumental factors with low $p$-values include:

- (I) 8: signage and next mode (with a $p$-value of 0.000 )

- (I) 1 : accessibility of the interchange ( $p$-value of 0.020 )

The attitudinal/affective factors with low $p$-values include:

- (A) 15: retail and commercial services at the interchange ( $p$-value of 0.000 )

- (A) 16: The shops are interesting ( $p$-value of 0.000$)$

- (A) 17: food and restaurants ( $p$-value of 0.000 )

- (A) 19: places to sit and wait ( $p$-value of 0.000)

- (A) 25: ambience is nice and comfortable ( $p$-value of 0.001 )

The findings suggest that the physical features of the hubs, such as walking distances, transfer times and provision of information, do not play a very important role in deciding whether a particular hub is attractive to the traveller, perhaps these are the areas that are well standardised, and that there is little difference between interchanges. However, the provision of shops, restaurants, entertainment, others services, $\mathrm{Wi}-\mathrm{Fi}$, the comfort of the waiting environment, and the ability to be productive whilst at the hub are important to consider if the attractiveness of an interchange hub is to be enhanced. These are often the areas of design that differ most between interchanges, with some excellent practice in particular locations, but often some very poor practice. A greater focus on improving the user experience within interchange design will help here.

Table 7: Experience at Different Hubs, Beijing South (BS), Chengdu East (CE) and Suzhou North (SN)

\begin{tabular}{|c|c|c|c|c|c|c|}
\hline Experiential Factors & $\begin{array}{c}\text { BS } \\
(N=\mathbf{5 0})\end{array}$ & $\begin{array}{c}\mathbf{C E} \\
(\mathbf{N}=\mathbf{5 0})\end{array}$ & $\begin{array}{c}\mathrm{SN} \\
(\mathbf{N}=\mathbf{5 0})\end{array}$ & $\begin{array}{c}\mathbf{F} \\
\text { statistic }\end{array}$ & $p$-value & Significance \\
\hline \multicolumn{7}{|l|}{ Instrumental } \\
\hline 1 (I) Access to the interchange is easy & 0.920 & 0.520 & 1.080 & 4.027 & 0.020 & $*$ \\
\hline 2 (I) Walking distance is short & 0.680 & 0.620 & 0.670 & 0.057 & 0.945 & \\
\hline 3 (I) There is little time to wait & 0.760 & 0.700 & 0.870 & 0.188 & 0.829 & \\
\hline 4 (I) It is quick to buy a ticket & 0.640 & 0.640 & 0.500 & 0.216 & 0.806 & \\
\hline $\begin{array}{l}5 \text { (I) I can easily find electronic } \\
\text { timetable information }\end{array}$ & 0.600 & 0.360 & 0.670 & 1.213 & 0.301 & \\
\hline $\begin{array}{l}6 \text { (I) Signing is clear and easy to } \\
\text { understand where to go }\end{array}$ & 0.560 & 0.480 & 0.210 & 2.085 & 0.128 & \\
\hline $\begin{array}{l}7 \text { (I) Access to the interchange is } \\
\text { convenient and pleasant }\end{array}$ & 0.720 & 0.460 & 0.440 & 1.275 & 0.283 & \\
\hline $\begin{array}{l}8 \text { (I) I can easily choose my next mode } \\
\text { and find its location using the signs }\end{array}$ & 0.600 & 1.240 & 0.000 & 16.912. & 0.000 & $* * *$ \\
\hline \multicolumn{7}{|l|}{ Attitudinal/Affective } \\
\hline 9 (A) I feel safe and secure in the hub & 0.780 & 0.62 & 0.48 & 1.00 & 0.369 & \\
\hline $\begin{array}{l}10 \text { (A) The hub is not too busy with } \\
\text { other people }\end{array}$ & 0.760 & 0.30 & 0.52 & 3.92 & 0.022 & $*$ \\
\hline $\begin{array}{l}11 \text { (A) I don't feel anxious and } \\
\text { impatient }\end{array}$ & 1.280 & 0.48 & 0.94 & 5.85 & 0.004 & $* *$ \\
\hline $\begin{array}{l}12 \text { (A) I can use one ticket for the door- } \\
\text { to-door journey }\end{array}$ & 0.560 & 0.70 & 0.42 & 0.80 & 0.450 & \\
\hline
\end{tabular}




\begin{tabular}{|c|c|c|c|c|c|c|}
\hline $\begin{array}{l}13 \text { (A) There are facilities for people } \\
\text { with disabilities and luggage }\end{array}$ & 0.640 & 0.60 & 0.40 & 0.98 & 0.376 & \\
\hline 14 (A) Security check is quick & 0.360 & 0.72 & 0.27 & 2.61 & 0.077 & \\
\hline $\begin{array}{l}15(\mathrm{~A}) \text { There is a variety of retail } \\
\text { services }\end{array}$ & -0.220 & 0.68 & 0.71 & 10.82 & 0.000 & $* * *$ \\
\hline 16 (A) The shops are interesting & -0.320 & 0.64 & 0.33 & 10.05 & 0.000 & $* * *$ \\
\hline 17 (A) I am happy with the restaurants & -0.060 & 0.88 & 0.77 & 8.84 & 0.000 & $* * *$ \\
\hline 18 (A) There are facilities for children & -0.280 & 0.00 & 0.15 & 3.43 & 0.035 & * \\
\hline 19 (A) There are places to sit and wait & 1.340 & 0.32 & 1.17 & 12.46 & 0.000 & $* * *$ \\
\hline $\begin{array}{l}20 \text { (A) The toilets are clean and easy to } \\
\text { use }\end{array}$ & 0.560 & 0.60 & 0.67 & 0.20 & 0.822 & \\
\hline 21 (A) Wi-Fi is available and free & 1.020 & 1.02 & 0.42 & 3.51 & 0.032 & $*$ \\
\hline $\begin{array}{l}22(\mathrm{~A}) \text { The architectural design is } \\
\text { characteristic and inspiring }\end{array}$ & 0.000 & 0.50 & 0.31 & 2.24 & 0.110 & \\
\hline $\begin{array}{l}23(\mathrm{~A}) \text { The hub is not affected by } \\
\text { weather }\end{array}$ & 0.380 & 0.66 & 0.56 & 1.36 & 0.259 & \\
\hline $\begin{array}{l}24(\mathrm{~A}) \text { The public realm is attractive } \\
\text { and pleasant }\end{array}$ & 0.640 & 0.48 & 0.62 & 0.33 & 0.717 & \\
\hline $\begin{array}{l}25 \text { (A) The ambience is nice and } \\
\text { comfortable }\end{array}$ & 1.040 & 0.32 & 0.48 & 7.12 & 0.001 & $* * *$ \\
\hline $\begin{array}{l}26 \text { (A) The staff at the interchange are } \\
\text { pleasant and helpful }\end{array}$ & 0.920 & 0.40 & 0.81 & 4.00 & 0.020 & * \\
\hline $\begin{array}{l}27 \text { (A) I can enjoy the view and } \\
\text { scenery }\end{array}$ & 0.080 & 0.38 & 0.54 & 2.66 & 0.074 & \\
\hline 28 (A) I can use my time productively & 0.680 & 0.42 & 0.62 & 0.77 & 0.464 & \\
\hline 29 (A) I can read or listen to music & 0.580 & 0.36 & 0.23 & 1.45 & 0.238 & \\
\hline 30 (A) I feel happy and relaxed & 0.800 & 0.32 & 0.17 & 6.13 & 0.003 & $* *$ \\
\hline
\end{tabular}

To gain further insight, we also conducted a factorial (three-way) MANOVA analysis to explore the influence of other factors apart from hubs on the interchange experience. These additional factors include respondent salaries and trip purposes, which reflect the socialeconomic characteristics of the travellers rather than the facilities of the hubs. Table 8 summarises the significance of these factors in the three-way MANOVA. Columns 4-7 refer to the 'combined effects' of these factors - reflecting the correlations between different factors and their 'joint' impact on the interchange experience, e.g. Column 4 (Hub/Salary) is the combined effect of hubs and salaries, Column 5 (Hub/Purpose) is the combined effect of hubs and trip purposes, Column 6 (Salary/Purpose) is the combined effect of salary and trip purposes, and Column 7 is the combined effect of all three factors. The first column (Hub) is consistent with the results shown earlier (Table 7) where we look at the factor 'Hub' alone. The second column (Salary) shows that the level of travellers' salaries has a significant impact on their instrumental experience for the following criteria:

- (I) 6: signing is clear and easy to understand where to go ( $p$-value of 0.005 )

- (I) 7: access to the interchange is convenient and pleasant ( $p$-value of 0.006)

And reasonably significant for:

- (I) 1: accessibility of the interchange ( $p$-value of 0.045 )

- (I) 3: there is little time to wait ( $p$-value of 0.043 ) 
The attitudinal/affective factors with low $p$-values with respect to 'Salary' include:

- (A) 11: I don't feel anxious and impatient ( $p$-value of 0.000$)$

- (A) 14: security check is quick ( $p$-value of 0.000 )

- (A) 18: there are facilities for children ( $p$-value of 0.001)

Table 8: Three-way MANOVA Experience at Different Hubs, Salaries and Trip Purposes

\begin{tabular}{|c|c|c|c|c|c|c|c|}
\hline & $\underline{\underline{\Xi}}$ & 冚 & 苋 & 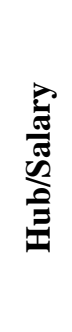 & 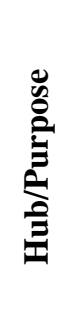 & 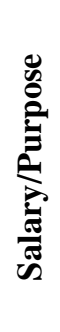 & 总 \\
\hline \multicolumn{8}{|l|}{ Instrumental } \\
\hline 1 (I) Access to the interchange is easy & $*$ & * & & & & & \\
\hline \multicolumn{8}{|l|}{2 (I) Walking distance is short } \\
\hline 3 (I) There is little time to wait & & * & & * & & & \\
\hline 4 (I) It is quick to buy a ticket & & & & $*$ & & & \\
\hline \multicolumn{8}{|l|}{5 (I) I can easily find electronic timetable information } \\
\hline 6 (I) Signing is clear and easy to understand where to go & & $* *$ & & & & & \\
\hline 7 (I) Access to the interchange is convenient and pleasant & & $* *$ & & & & & \\
\hline $\begin{array}{l}8 \text { (I) I can easily choose my next mode and find its location using } \\
\text { the signs }\end{array}$ & $* * *$ & & & & & & \\
\hline \multicolumn{8}{|l|}{ Attitudinal/Affective } \\
\hline 9 (A) I feel safe and secure in the hub & & * & & & & & \\
\hline 10 (A) The hub is not too busy with other people & $*$ & & & & & & \\
\hline 11 (A) I don't feel anxious and impatient & $* *$ & $* * *$ & & & & & \\
\hline 12 (A) I can use one ticket for the door-to-door journey & & * & & * & & & $*$ \\
\hline \multicolumn{8}{|l|}{13 (A) There are facilities for people with disabilities and luggage } \\
\hline 14 (A) Security check is quick & & $* * *$ & & & & & \\
\hline 15 (A) There is a variety of retail services & $* * *$ & & & & & & \\
\hline 16 (A) The shops are interesting & $* * *$ & & & * & $* *$ & & \\
\hline 17 (A) I am happy with the restaurants & $* * *$ & & & & & & \\
\hline 18 (A) There are facilities for children & * & $* *$ & & $* * *$ & & & $*$ \\
\hline 19 (A) There are places to sit and wait & $* * *$ & & & & & & \\
\hline 20 (A) The toilets are clean and easy to use & & & & & & & $*$ \\
\hline 21 (A) Wi-Fi is available and free & $*$ & & & & & & \\
\hline 22 (A) The architectural design is characteristic and inspiring & & & & * & $* * *$ & & \\
\hline \multicolumn{8}{|l|}{23 (A) The hub is not affected by weather } \\
\hline 24 (A) The public realm is attractive and pleasant & & & & & $* *$ & & \\
\hline 25 (A) The ambience is nice and comfortable & $* * *$ & & & & & & \\
\hline 26 (A) The staff at the interchange are pleasant and helpful & * & & & & * & & \\
\hline 27 (A) I can enjoy the view and scenery & * & & & & & & \\
\hline
\end{tabular}




\begin{tabular}{|l|l|l|l|l|l|l|l|}
\hline 28 (A) I can use my time productively & & & & & & & \\
\hline 29 (A) I can read or listen to music & & & & & & & \\
\hline 30 (A) I feel happy and relaxed & $* *$ & & & $* *$ & & & \\
\hline
\end{tabular}

Notes: $* \mathrm{p}<.05 ; * * \mathrm{p}<.01 ; * * * \mathrm{p}<.001$

Most of the interchange experiences significantly affected by 'Hubs' do not coincide with those significantly affected by travellers' salaries. In general, experiences affected by 'Hubs' are dependent on the facilities and environment of the hubs, while experiences affected by 'Salary' perhaps tend to be more personal and related to the individual's characteristics (e.g. ease of reading information, anxiety, experience with security, etc.). An exception might be attitudinal factor 'A18' (there are facilities for children) which is significantly associated 'jointly' with 'Hubs' and 'Salary', with a $p$-value of 0.001. An explanation may be that there is a relationship between salary and the number of children within the passengers surveyed. For example, passengers who have a higher salary may be able to afford more children to travel with them, or perhaps they are at a later life stage where salaries have increased and children arrived. As a consequence, passengers or families with a higher income may be more concerned about the need for children's facilities at hubs.

It is also found that purpose of trip itself is not a significant factor on the interchange experience. When considered jointly with the 'Hubs' factor, it has a significant influence on:

- (A) 16: the shops are interesting (p-value of 0.002)

- (A) 22: the architectural design is characteristic and inspiring (p-value of 0.001)

- (A) 24: The public realm is attractive and pleasant (p-value of 0.002)

These factors reflect the availability of shops and the architectural design of the interchange and public realm. It suggests that travellers may pay more attention to these factors depending on their trip purposes. For example, more attention may be made to the architectural design of the hub if his/her trip purpose is for leisure travel rather business.

Finally, based upon the factorial analysis, we remove the insignificant experiences and regroup the significant ones according to their correlation. For instrumental factors, we create two categories:

- 'Accessibility of hubs': including factor 'I6' (i.e. signing is clear and it is easy to understand where to go) and 'I7' (i.e. access to the interchange is convenient and pleasant);

- 'Easiness of transfer': factor 'I8'.

For attitudinal/affective factors, we create the following three categories:

- 'Security': including factors 'A11' and 'A14';

- 'Service and entertainment': factors 'A15', 'A16', 'A17', 'A18', and 'A19';

- 'Design and public realm': factors 'A22', 'A24', and 'A25'.

The factorial MANOVA is re-run again after regrouping the experiences and the results are presented in Table 9. The table shows the five most significant categories of interchange experience associated with hubs and the social-economic characteristics of passengers. 
Table 9: Three-way MANOVA Experience at Different Hubs, Salaries and Trip Purposes (Regrouped Experiences)

\begin{tabular}{|l|l|l|l|l|l|l|l|}
\hline & & & & & & & \\
& & & & & & & \\
& & & & & & & \\
\hline Instrumental & & & & & & & \\
\hline (I) Accessibility of hubs & & $* *$ & & & & & \\
\hline (I) Easiness of transfer & $* * *$ & & & & & & \\
\hline Attitudinal/Affective & & & & & & & \\
\hline (A) Security & $* *$ & $* * *$ & & & & & \\
\hline (A) Services and entertainment & $* * *$ & $* *$ & & $* * *$ & $* *$ & & \\
\hline (A) Design and public realm & $* * *$ & & & $*$ & $* * *$ & & \\
\hline
\end{tabular}

Notes: $* \mathrm{p}<.05 ; * * \mathrm{p}<.01 ; * * * \mathrm{p}<.001$

\section{Conclusions}

The aspiration for HSR to shrink spaces and shape places (Banister et al., 2013) is contingent on a good design of the network and, perhaps critically, of the intermodal interchange hub. Some of the recent interchanges that have been developed in the PRC are very well designed and represent internationally-leading practice; these include hubs such as Shanghai South and Shanghai Hongqiao (Chen et al., 2014). Beyond these, a large number of hubs have less successful design. Most are faced with a range of issues, including:

- A rapidly increasing demand for travel, with a need in environmental and city design terms to accommodate huge growth on the public transport network;

- Hubs are often built considering future passenger projections, and can involve very large, multi-level spaces, hence at the start of operation can be large and unwelcoming places to be. Although hubs may be designed well in instrumental terms they are often less attractive in attitudinal/affective journey experience terms;

- Particular parts of the interchange can be subject to congestion and queuing, often due to the security check, reducing the quality of the journey experience. Increasing passenger expectations of speed, convenience, safety, security, comfort, and enjoyment are not always met;

- Different needs of passengers and other users, including those with accessibility difficulties, are not always catered for;

- Increasing possibilities in electronic interaction, using mobile phones and tablets, make information access and entertainment much easier while traveling, and offer great potential for improving the productivity of travel.

Similar to other modes of travel, the utility of public transport extends beyond the instrumental factors, and includes attitudinal and affective dimensions. Perhaps, in time, there can even be greater status involved in the use of public transport. This paper has sought to examine the growth of HSR in the PRC and, as part of this, the development of major intermodal interchange hubs. It has analysed the experience of the journey through the interchange, using three selected intermodal HSR hubs, representing super large, large, and medium rail hubs in the PRC. Although there is likely to be some overlap between instrumental, attitudinal and affective factors, e.g. improving the speed or reducing the cost of the journey may also improve the experiential factors, the approach used attempts to highlight 
the importance of attitudinal issues alongside the instrumental, and the importance of expected facilities relative to realised facilities. The main argument made is that the attitudinal and affective factors need much greater attention in the design of interchanges in the PRC - seamlessness in travel has multiple dimensions, and perhaps over time it is the attitudinal and affective nature of travel that will become most important. The time 'in journey' can become much less significant. There are many common problems across the selected interchanges in the PRC, including Wi-Fi availability, waiting and seating, the availability of door-to-door ticketing, crowdedness, access to the hub, and the extent of time of travel through and waiting in the hub. MANOVA analysis shows how there are large differences between intermodal hubs, with many instrumental and particularly attitudinal factors being significantly influenced by location.

The interchange has conventionally been viewed as 'wasted time', and a part of the door-todoor journey that should be avoided or removed wherever possible. Indeed many public transport passengers do seek to avoid the interchange part of the journey. But, with the possibilities now on offer, in design and technology terms, this seems be changing. The leading-edge interchanges now being designed and built, including in the PRC, offer a much improved journey experience. Passengers are starting to use them in very different ways, the experience of the journey is beginning to improve, and perhaps the concept of wasted time (and, consequently, of time savings) is becoming out-dated: the journey time can become part of everyday life, with enjoyment and productivity little different from being in the office, at home, or elsewhere. Zajonc (1980, p.153-154) reminds us that: "there are very few perceptions and cognitions in everyday life that do not have a significant affective component, that aren't hot, or in the very least tepid [...] we do not just see 'a house', we see 'a handsome house' or 'an ugly house'. The same applies in our use of public transport, and it is this emerging experiential phenomenon that we can seek to further understand, and to enhance and develop, across the PRC and internationally.

\section{Acknowledgements}

Many thanks to the Asian Development Bank for supporting the research reported on in this paper; and to the research teams at Tsinghua University, Xi'an Jiatong-Liverpool University and Southwest University for Nationalities for carrying out the surveys. Also to two anonymous reviewers, whose comments much improved the paper.

\section{References}

Anable, J. 2005. 'Complacent Car Addicts' or `Aspiring Environmentalists'? Identifying travel behaviour segments using attitude theory. Transport Policy, 12, 65-78.

Anable, J. and Gatersleben, B. 2005. All work and no play? The role of instrumental and affective factors in work and leisure journeys by different travel modes. Transportation Research, Part A, 39, 163-181.

Banister, D., Hall, P. and Marshall, S. 2013. High-speed rail: shrinking spaces, shaping places. Built Environment, 39, 321-323.

Brons, M. and Rietveld, P. 2009. Improving the quality of the door-to-door rail journey: a customeroriented approach. Built Environment, 35, 122-135.

Carreira, R., Patrício, L., Natal Jorge, R. \& Magee, C. 2014. Understanding the travel experience and its impact on attitudes, emotions and loyalty towards the transportation provider-A quantitative study with mid-distance bus trips. Transport Policy, 31, 35-46.

Carreira, R., Patrício, L., Natal Jorge, R., Magee, C. and Van Eikema Hommes, Q. 2013. Towards a holistic approach to the travel experience: A qualitative study of bus transportation. Transport Policy, 25, 233-243. 
Chen, C-L. 2012. Reshaping Chinese space-economy through high-speed trains: opportunities and challenges. Journal of Transport Geography, 22, 312-316.

Chen, C-L., Hickman, R. and Saxena, S. 2014. Improving Interchanges. Towards Better Multimodal Hubs in the PRC. Manila: Asian Development Bank.

Dai, S. 2011. Urban Transport Planning in the ear of High-Speed Rail (The Phonetic Title: Gaotie Shidaide Chengshi Jiaotong Guihua), Beijing China Building Bookshop.

Dell'Olio, L., Ibeas, A. and Cecin, P. 2011. The quality of service desired by public transport users. Transport Policy, 18(1), 217-227.

Eboli, L. and Mazzulla, G. (2011). A methodology for evaluating transit service quality based on subjective and objective measures from the passenger's point of view. Transport Policy, 18(1): 172-181.

Givoni, M. and Rietveld, P. 2007. The access journey to the railway station and its role in passengers' satisfaction with rail travel. Transport Policy, 14, 357-365.

Green, C. and Hall, P. 2009. Better Rail Stations: An Independent Review (presented to Lord Adonis, Secretary of State for Transport), London, Department for Transport.

Hall, P. 2009. Magic carpets and seamless webs: opportunities and constraints for hgh-speed trains in Europe. Built Environment, 35, 59-69.

Hamiduddin, I., Hall, P., Hickman, R., Jones, P. and Osborne, C. 2013. S-MAP 2030: An Action Plan for Seamless Mobility in North West Europe. Eindhoven: EU INTERREG IVB, SYNAPTIC Project.

Hickman, R., Hamiduddin, I., Hosea, B., Roberts, S., Hall, P., Jones, P. and Osborne, C. 2013. Animating the future seamless public transport journey. Built Environment, 39, 369-384.

Hickman, R., Hamiduddin, I., Sellmann, T., Hall, P., Jones, P. and Osborne, C. 2012. S-MAP 2030: Achieving seamless mobility in Europe. Technical paper, analysis of journey experiences across North West Europe. London: University College London.

Hine, J. and Scott, J. 2000. Seamless, accessible travel: users' views of the public transport journey and interchange. Transport Policy, 7, 217-226.

Jain, J. and Lyons, G. 2008 The gift of travel time. Journal of Transport Geography, 16(2), 81-89.

Lyons, G. and Urry, J. 2005. Travel time use in the information age. Transportation Research, Part A, 39(2), 257-276.

Metrolinx. 2011. Mobility Hub Guidelines. Toronto: Metrolinx.

Ministry of Railways. 2007. Code for Design of Railway Passenger Station Buildings. GB 502262007. Beijing: China Planning Press.

Mokhtarian, P. and Salomon, I. 2001. How derived is the demand for travel? Some conceptual and measurement considerations. Transportation Research, Part A, 35(8), 695-719.

National Bureau of Statistics of China. 2012. China Population and Employment Statistics Yearbook, 2011, Beijing: China Statistics Press.

National People's Congress. 2011. Twelfth Five-Year Plan, 2011-2015. Xinhua News Agency, 16 March.

Price, L. and Matthews, B. 2013. Travel time as quality time: parental attitudes to long distance travel with young children. Journal of Transport Geography, 32, 49-55.

Steg, L. 2005. Car use: lust and must. Instrumental, symbolic and affective motives for car use. Transportation Research, Part A, 39, 147-162.

Stradling, S., Anable, J. and Carreno, M. 2007. Performance, importance and user disgruntlement: A six-step method for measuring satisfaction with travel modes. Transportation Research, Part A, 41, 98-106.

Taylor, J. 2012. Good Practice in Transport Interchanges. London: EU INTERREG IVB, SINTROPHER Project, UCL.

Tertoolen, G., Van Kreveld, D. and Verstraten, B. 1998. Psychological resistance against attempts to reduce private car use. Transportation Research, Part A, 32, 171-181.

Third Railway Survey and Design Institute. 2005. Code for Design on Accessibility of railway Passenger Station Buildings. TB 10083-2005 and J458-2005. Beijing: China Railway Publishing House.

Transport for London. 2009. Interchange Best Practice Guidelines. London: TfL. 
UIC International Union of Railways. 2011. Benchmark of Asian Public Transport Interchanges. Executive Summary. Brussels: TU Delft, UIC.

World Bank. 2013. World Development Indicators, Country Data. Washington: World Bank.

Xiao, J. and Yuan, Z. 2007. China will build 10 major urban agglomerations to dominate the future development of the national economy. China Economic Times. 29 March.

Zajonc, R. 1980. Feelings and thinking: preferences need no inferences. American Psychologist, 35, 151-175.

Zhang, G., Huang, L. and Wang, Y. 2010. From city centre to city gate. The development tendency of town and country spatial structure through the construction of high-speed transport network (in Chinese). Annual National Planning Conference of China. Chongqing, China, 15-17 October. 